\title{
Obstetric hysterectomy, still a life saving tool in modern day obstetrics: a five year study
}

\author{
Neetu Singh*, Kiran Pandey, Renu Gupta, Shaily Agarwal, Amita Chaudhary, Ani
}

Department of Obstetrics \& Gynaecology, G.S.V.M. Medical College, Kanpur-208002, Uttar Pradesh, India

Received: 31 May 2014

Accepted: 10 June 2014

\author{
*Correspondence: \\ Dr. Neetu Singh, \\ E-mail: dr.neetusingh73@gmail.com,drneetusingh73@gmail.com
}

(C) 2014 Singh N et al. This is an open-access article distributed under the terms of the Creative Commons Attribution Non-Commercial License, which permits unrestricted non-commercial use, distribution, and reproduction in any medium, provided the original work is properly cited.

\begin{abstract}
Background: Objective of current study was to study the indications and maternal outcome of emergency obstetric hysterectomy and its role in reduction of maternal morbidity and mortality in complicated obstetric cases.

Methods: A prospective study of the cases of emergency obstetric hysterectomy performed over a period of five years from 2009 to 2013 was done.

Results: During the study period, 105 emergency obstetric hysterectomies were performed giving an incidence of $0.54 \%$.The incidence of hysterectomy following vaginal delivery was $0.54 \%$ and that of caesarean hysterectomy was $2.08 \%$. It was most common in the age group 26-35 years $(66.66 \%)$ and in women of parity 3-4 (71.42\%).Rupture uterus was the most common indication accounting for 59.04\% cases followed by Atonic PPH (18.09\%). Febrile illness and wound infection were the two most common co-morbidities. Maternal mortality was $5.71 \%$.

Conclusions: Emergency obstetric hysterectomy is potentially a life saving procedure which every obstetrician must be familiar with in cases of catastrophic rupture uterus and intractable haemorrhage. With the help of prostaglandins, modern policies of active management of labor, timely performance of caesarean section, internal iliac artery ligation, compression sutures etc. obstetric hysterectomy should be made a more rare procedure
\end{abstract}

Keywords: Obstetric hysterectomy, Emergency hysterectomy, Post-partum hysterectomy

\section{INTRODUCTION}

Emergency Obstetric Hysterectomy (EOH) is an uncommon obstetric procedure, usually performed as a life-saving measure in cases of intractable obstetric hemorrhage. ${ }^{1}$ It was first proposed in 1869 but with no desirable results. ${ }^{2}$ However, seven years later (1876), the first cesarean subtotal hysterectomy was carried out successfully, with the result that both the mother and the baby survived. ${ }^{3}$ In modern obstetrics, the overall incidence of $\mathrm{EOH}$ is $0.05 \%$, but there are considerable differences in incidence in different parts of the world, depending on modern obstetric services, standards and awareness of antenatal care, and the effectiveness of family planning activities of a given community. ${ }^{4}$ The incidence of peripartum hysterectomy in the literature is reported as $0.24,0.77,2.3$, and 5.09 per 1000 deliveries by Sakse et al., ${ }^{5}$ Whiteman et al., ${ }^{6}$ Bai et al. ${ }^{7}$ and Zeteroglu et al., ${ }^{8}$ respectively.

Emergency obstetric hysterectomy remains an essential weapon in any obstetrician's armory. Hence, it is important to know the general indices, changing trends and indications of this weapon. Keeping this in mind, the present study was undertaken with an aim to evaluate the incidence, maternal profile, indications and maternal outcome of this procedure.

\section{METHODS}

This is a retrospective analysis of 105 cases of emergency obstetric hysterectomies performed over a period of five years from 2009 to 2013 in department of obstetrics and gynaecology, GSVM medical college, Kanpur. Data were 
obtained by reviewing the obstetric admission register, operation register, mortality register and case records. Each case record was analyzed in detail with special emphasis on indications, maternal profile, type of operation performed, maternal morbidity and mortality and also fetal outcome.

Hysterectomy performed for any indication during pregnancy, labor and puerperium has been included on this study.

\section{RESULTS}

Over the period of five years, out of the total 19125 deliveries, there were 150 cases of rupture uterus, giving an incidence of $0.78 \%$ ( 1 in 127 deliveries). Out of the 19125 deliveries, obstetric hysterectomy was performed in 105 cases $(0.54 \%)$,

\section{Incidence}

During the study period there were 19125 deliveries, 5025cesarean sections and 105 obstetric hysterectomies. The incidence works out to be one in 182.1 deliveries $(0.54 \%)$ and one in $47.8(2.08 \%)$ cesarean sections.

\section{Distribution of cases according to socio-economic status, antenatal care and residence}

Table 1 shows that $71.42 \%$ women were of parity three and four, while $9.5 \%$ were of parity five or more. Majority $(66.66 \%)$ of the women belonged to the age group of 26-35 years. Two women were in the age group 18-20 years.

Table 1: Maternal characteristics.

\begin{tabular}{|lllllll|}
\hline Age & $\mathbf{1}$ & $\mathbf{2}$ & $\mathbf{3}$ & $\mathbf{4}$ & $\begin{array}{l}\mathbf{5} \text { or } \\
\text { more }\end{array}$ & Total \\
\hline 20 or less & 2 & - & - & - & - & 2 \\
\hline $21-25$ & 2 & 4 & 8 & 2 & - & 16 \\
\hline $26-30$ & - & 8 & 26 & 2 & 4 & 40 \\
\hline $31-35$ & - & 4 & 10 & 10 & 6 & 30 \\
\hline $36-40$ & - & - & 7 & 10 & - & 17 \\
\hline Total & 4 & 16 & 51 & 24 & 10 & 105 \\
\hline
\end{tabular}

Table 2 shows that $80 \%$ cases were of poor socioeconomic status $20 \%$ belong to middle class. Out of 105 patients, only $10(9.52 \%)$ cases were booked. In our series $85.71 \%$ cases belonged to rural area.

Table 2: Distribution of cases according to socio-economic status, antenatal care and residence.

\begin{tabular}{|lllllll|} 
& \multicolumn{2}{c}{ Socioeconomic status } & \multicolumn{2}{c|}{ Antenatal care } & \multicolumn{2}{l|}{ Residence } \\
& Poor & Middle & Unbooked & Booked & Rural & Urban \\
\hline No. of cases & 84 & 21 & 95 & 10 & 90 & 15 \\
\hline Percentage & 80 & 20 & 90.47 & 9.52 & 85.71 & 14.28 \\
\hline
\end{tabular}

Table 3 shows that the most common indication for hysterectomy was rupture uterus (62/105); (59.04\%). Table 3 further shows that the second most common indication was atonic PPH $(19 / 105 ; 18.09 \%)$ not amenable to medical methods and brace sutures. Most of them followed prolonged labor, five cases followed abruption.

Table 3: Indications of obstetric hysterectomy $(\mathbf{n}=105)$.

\begin{tabular}{|lll|}
\hline Indication & No. & $\%$ \\
\hline Rupture uterus & 62 & $59.04 \%$ \\
\hline Atonic PPH & 19 & $18.09 \%$ \\
\hline MTP with perforation & 5 & $4.76 \%$ \\
\hline Placenta accreta & 15 & $14.28 \%$ \\
\hline Broad lig. Hematoma & 4 & $3.80 \%$ \\
\hline Total & 105 & $100 \%$ \\
\hline
\end{tabular}

Fifteen (14.28\%) women had hysterectomy for placenta accreta. Seven of them had previous cesarean scar, four had placenta previa, two had previous cesarean scar with placenta previa, and two had placenta percreta. In four women $(3.80 \%)$, hysterectomy was done for broad ligament hematoma resulting from the extension of uterine incision. There were five cases $(4.76 \%)$ of uterine perforation at lateral wall with profuse hemorrhage following MTP requiring hysterectomy.

Table 4 shows that 100 out of the $150(66.66 \%)$ cases of rupture uterus were obstructive rupture. $20 \%$ cases of rupture uterus were due to previous scar rupture. Most of them had previous cesarean scar. Among these 14 patients had previous classical scar and 11 had lower segment scar. ${ }^{9,10}$

Table 4: Causes of rupture uterus $(n=150)$.

\begin{tabular}{|lll|}
\hline Causes & No. & $\%$ \\
\hline Spontaneous obstructive rupture & 100 & $66.66 \%$ \\
\hline Previous LSCS scar rupture & 30 & $20 \%$ \\
\hline Other causes & 20 & $13.33 \%$ \\
\hline Total & 16 & $100 \%$ \\
\hline
\end{tabular}




\section{Maternal outcome}

Table 5 summarizes the maternal morbidity and mortality. Febrile morbidity was the commonest postoperative complication $(28.57 \%)$, followed by wound infection $(23.80 \%)$. Five $(4.76 \%)$ cases had burst abdomen. There were six maternal deaths, giving $5.71 \%$ maternal mortality. These resulted from hemorrhagic shock in three, endotoxic shock in two and DIC in one case. Perinatal mortality was $85.71 \%$ (90/105 cases) with only 15 live births.

Table 5: Maternal morbidity and mortality.

\begin{tabular}{|lll|}
\hline Indication & No. & $\%$ \\
\hline Febrile morbidity & 30 & $28.57 \%$ \\
\hline Wound infection & 25 & $23.80 \%$ \\
\hline Burst abdomen & 5 & $4.76 \%$ \\
\hline Paralytic ileus & 10 & $9.52 \%$ \\
\hline Maternal mortality & 6 & $5.71 \%$ \\
\hline - $\quad$ Hemorrhagic shock & 3 & \\
\hline - $\quad$ Endotoxic shock & 2 & \\
\hline - $\quad$ DIC & 1 & \\
\hline
\end{tabular}

Table 6 shows a comparison of the incidence and indications of obstetric hysterectomy of various reported series from India.

Table 6: Comparison with other reported series.

\begin{tabular}{|lllll|}
\hline Authors & $\begin{array}{l}\text { Incidence } \\
(\%)\end{array}$ & $\begin{array}{l}\text { Major indications } \\
\text { Rupture } \\
\text { uterus }\end{array}$ & $\begin{array}{l}\text { Atonic } \\
\text { PPH }\end{array}$ & $\begin{array}{l}\text { Placenta } \\
\text { accreta }\end{array}$ \\
\hline $\begin{array}{l}\text { Gupta et al. } \\
(2001)\end{array}$ & 0.26 & 69.7 & 9.70 & 6.30 \\
\hline $\begin{array}{l}\text { Kore et al. } \\
(2001)\end{array}$ & 0.18 & 38.20 & 32.30 & 5.88 \\
\hline Sinha $^{17}$ (2001) & 0.38 & 69.92 & 9.80 & 12.57 \\
\hline $\begin{array}{l}\text { Mukherjee } \\
(2002)\end{array}$ & 0.15 & 38.30 & 14.90 & 8.40 \\
\hline $\begin{array}{l}\text { Kanwar et al. } \\
(2003)\end{array}$ & 0.32 & 36.58 & 31.71 & 14.63 \\
\hline $\begin{array}{l}\text { Praneshwari } \\
\text { Devi }{ }^{11} \text { (2004) }\end{array}$ & 0.07 & 23.00 & 19.20 & 26.90 \\
\hline Sahu (2004) & 0.20 & 38.88 & 27.70 & 13.88 \\
\hline $\begin{array}{l}\text { Present series } \\
(\mathbf{2 0 1 4})\end{array}$ & 0.54 & 59.04 & 18.09 & 14.28 \\
\hline
\end{tabular}

\section{DISCUSSION}

It is essential that every obstetrician should be familiar with the indications and the skill to do this operation. Senior obstetricians should be available but resident doctors should be adequately trained to perform a quick subtotal hysterectomy. Most of the hysterectomies in our series were performed by the senior residents on duty outside of routine working hours. Incidence of emergency obstetric hysterectomy in our series is $0.54 \%$ which is much higher than other reported series; $0.07 \%$ by
Praneshwari Devi et al., ${ }^{11} 0.15 \%$ by Mukherjee, ${ }^{12} 0.18 \%$ by Kore et al., ${ }^{13} 0.2 \%$ by Sahu et al., ${ }^{14} 0.26 \%$ by Gupta, ${ }^{15}$ $0.32 \%$ by Kanwar et al., ${ }^{16}$ and $0.38 \%$ by Sinha. ${ }^{17}$ Rupture uterus was the commonest indication for emergency obstetric hysterectomy in our series accounting for $59.04 \%$ of the cases. All these women were un-booked emergency cases belonging to the low socioeconomic group, resulting from neglected obstetric care and delayed transport. This incidence is much similar to $69.9 \%$ reported by $\operatorname{Sinha}^{17}$ and $69.7 \%$ reported by Gupta. ${ }^{15}$ However, Sahu ${ }^{14}$ and Mukherjee ${ }^{12}$ reported a lesser incidence of about 38\%. Atonic PPH (18.09\%) was the second most common indication followed by placenta accreta $(14.28 \%)$ in our series. This is in contrast to the study by Praneshwari Devi ${ }^{11}$ where morbid adhesion of placenta $(26.9 \%)$ was the commonest indication for obstetric hysterectomy, followed by rupture uterus $(23.00 \%)$. Lau et al. ${ }^{18}$ have also reported morbid adhesion of placenta $(32.7 \%)$ as the most common cause of haemorrhage and hysterectomy.

Morbidity and mortality are mainly due to the conditions leading to emergency hysterectomy and not due to the operative procedure itself.

In our study also, the indication itself and the associated factors like anemia, handling by untrained dais, infection, delayed referral or transport and low moribund conditions were mainly responsible for morbidity and mortality.

\section{CONCLUSION}

Obstetric hysterectomy is a life saving procedure in most of the cases. In spite of development of various conservative medical management and surgical procedures to cut of possibility of obstetric hysterectomy, various patients are referred to our side in such a condition that the surgeon is sometimes in a dilemma whether to sacrifice a woman's reproductive capability especially if she is of low parity. But a timely decision to perform hysterectomy can be the difference between the life and death of a woman. A quick subtotal hysterectomy usually saves life in conditions of acute blood loss and shock. Regular antenatal care, identification of high risk factors at periphery and timely referral to higher center not only saves mother but also their reproductive capability. Adequate training of resident doctors to perform obstetric hysterectomy in an emergency situation is of utmost importance. Educating the woman, her family members and the local population is equally important to avail immediate obstetric care rather than giving unnecessary trial at home by unskilled persons. Timely referral to a tertiary centre can reduce morbidity and mortality.

\section{Funding: No funding sources \\ Conflict of interest: None declared}

Ethical approval: The study was approved by the institutional ethics committee 


\section{REFERENCES}

1. Rossi AC, Lee RH, Chmait RH. Emergency postpartum hysterectomy for uncontrolled postpartum bleeding: a systematic review. Obstet Gynaecol. 2010;115:637-44.

2. Daskalakis G, Anastasakis E, Papantoniou N, Mesogitis S, Theodora M, Antsaklis A. Emergency obstetric hysterectomy. Acta Obstet Gynecol Scand. 2007;86:223-7.

3. Sturdee D, Rushton D. Caesarian and post-partum hysterectomy, 1968-1983. Br J Obstet Gynaecol. 1986;93:270-4.

4. E. H. Park, B. P. Sachs. Post-partum haemorrhage and other problems of third stage. In: D. K. James, P. J. Steer, C. P. Weiner, B. Gonik, eds. High Risk Pregnancy: Management Options. 2nd ed. Philadelphia, Pa, USA: W.B. Saunders; 1999: 1231 1246.

5. A. Sakse, T. Weber, C. Nickelsen, N. J. Secher, Peripartum hysterectomy in Denmark, 1995-2004. Acta Obstet Gynaecol Scand. 2007;86(12):1472-5.

6. M. K. Whiteman, E. Kuklina, S. D. Hillis et al. Incidence and determinants of peripartum hysterectomy. Obstet Gynaecol. 2006;108(6):148692.

7. S. W. Bai, H. J. Lee, J. S. Cho, Y. W. Park, S. K. Kim, K. H. Park. Peripartum hysterectomy and associated factors. J Reprod Med Obstet Gynaecol. 2003;48(3):148-52.

8. S. Zeteroglu, Y. Ustun, Y. Engin-Ustun, G. Sahin, M. Kamaci. Peripartum hysterectomy in a teaching hospital in the eastern region of Turkey. Eur J Obstet Gynaecol Reprod Biol. 2005;120(1):57-62.
9. Green R, Gardiel, Turner M. Long term complications of caesarian section. Am J Obstet Gynaecol. 1997;176(1):245-5.

10. Mukherjee J, Roychowdhury J. Rupture uterus - a clinical study of 70 cases. J Obstet Gynec India 1995;45:85-9.

11. Praneshwari Devi RK, Singh NN, Singh TD. Emergency obstetric hysterectomy. J Obstet Gynaecol India. 2004;54:127-9.

12. Mukherjee P, Mukherjee G, Das C. Obstetric hysterectomy: a review of 107 cases. J Obstet Gynaecol India. 2002;52:34-6.

13. Kore S, Potwar S, Tamboli $\mathbf{J}$ et al. Obstetric hysterectomy analysis of 34 cases. J Obstet Gynaecol India. 2001;51:94-6.

14. Sahu L, Chakravertty B, Panda S. Hysterectomy for obstetric emergencies. J Obstet Gynaecol India. 2004;54:34-6.

15. Gupta S, Dave A, Bandi $G$ et al. Obstetric hysterectomy in modern day obstetrics: a review of 175 cases over a period of 11 years. J Obstet Gynaecol India. 2001;51:91-3.

16. Kanwar M, Sood PL, Gupta KB et al. Emergency hysterectomy in obstetrics. J Obstet Gynaecol India. 2003;53:350-2.

17. Sinha HH, Mishra MG. Hysterectomy for obstetric emergencies. J Obstet Gynaecol India. 2001;51:1114.

18. Lau WC, Fung HY, Rogers MS. Ten years experience of cesarean and postpartum hysterectomy in a teaching hospital in Hong Kong. Eur J Obstet Gynaecol Reprod Biol. 1997;74:133-7.

DOI: $10.5455 / 2320-1770$. ijrcog20140915

Cite this article as: Singh N, Pandey K, Gupta R, Agarwal S, Chaudhary A, Ani. Obstetric hysterectomy, still a life saving tool in modern day obstetrics: a five year study. Int J Reprod Contracept Obstet Gynecol 2014;3:540-3. 